\title{
Posterior Transpetrosal Approach
}

\author{
鰐㴊 昌彦 \\ 札幌医科大学医学部脳神経外科
}

\section{Posterior Transpetrosal Approach}

\author{
Masahiko Wanibuchi, M.D., Ph.D. \\ Department of Neurosurgery, Sapporo Medical University School of Medicine
}

The posterior transpetrosal approach, which can provide a better ventral surgical view than the lateral suboccipital approach, is required for the surgical treatment of skull base lesions extending to the petrous bone. In this paper, the microsurgical anatomy of the mastoid and surgical manipulation involved in mastoidectomy are explained.

The posterior transpetrosal approach for petroclival lesions has been reported from the 1970s to the early 1990s. This approach is typically performed in combination with other approaches, leading to several variations. The surgery is performed in the lateral position. The posterior neck muscles are retracted to avoid muscle injury. After the occipital bone and mastoid had been exposed, occipital craniotomy and mastoidectomy are performed. A triangular shape is drilled into the mastoid with the following anatomical landmarks as vertices: the posterior point of the root of the zygoma, mastoid tip, and asterion. Subsequently, the sigmoid sinus plate and mastoid antrum are exposed. After confirming the lateral semicircular canal inside the mastoid antrum, the superior and posterior semicircular canals are also exposed. Finally, the facial nerve and jugular bulb are identified.

Precise anatomical knowledge and a safe skull base drilling technique are required to achieve success with the use of the posterior transpetrosal approach, resulting in a wide and shallow surgical field for skull base lesion.

(Received February 5, 2018; accepted February 14, 2018)

Key words : posterior transpetrosal approach, mastoidectomy, skull base surgery Jpn J Neurosurg (Tokyo) $27: 828-834,2018$

\section{はじめに}

後頭蓋窩外側病変に対する手術では, lateral suboccipital approach が基本となる。しかし，錐体骨にまで病変が 及ぶ頭蓋底病変で，より腹側からの術野が必要になる場 合には, mastoidectomy が必要となる. S 状静脈洞の腹側 より到達する posterior transpetrosal approach について, 歴史的背景, 概念, 錐体骨の解剖, mastoidectomy の仕
方，臨床例につき解説する。

\section{歴史的背景}

Unpublished data のため論文で確認することはできな いが，1965 年に Henderson が錐体骨と側頭骨を drilling して上錐体静脈洞を切断し, 聴神経腫瘍や斜台部髄膜腫 を摘出したとの記載がある ${ }^{6) 9}$. その後, 1970 年には 


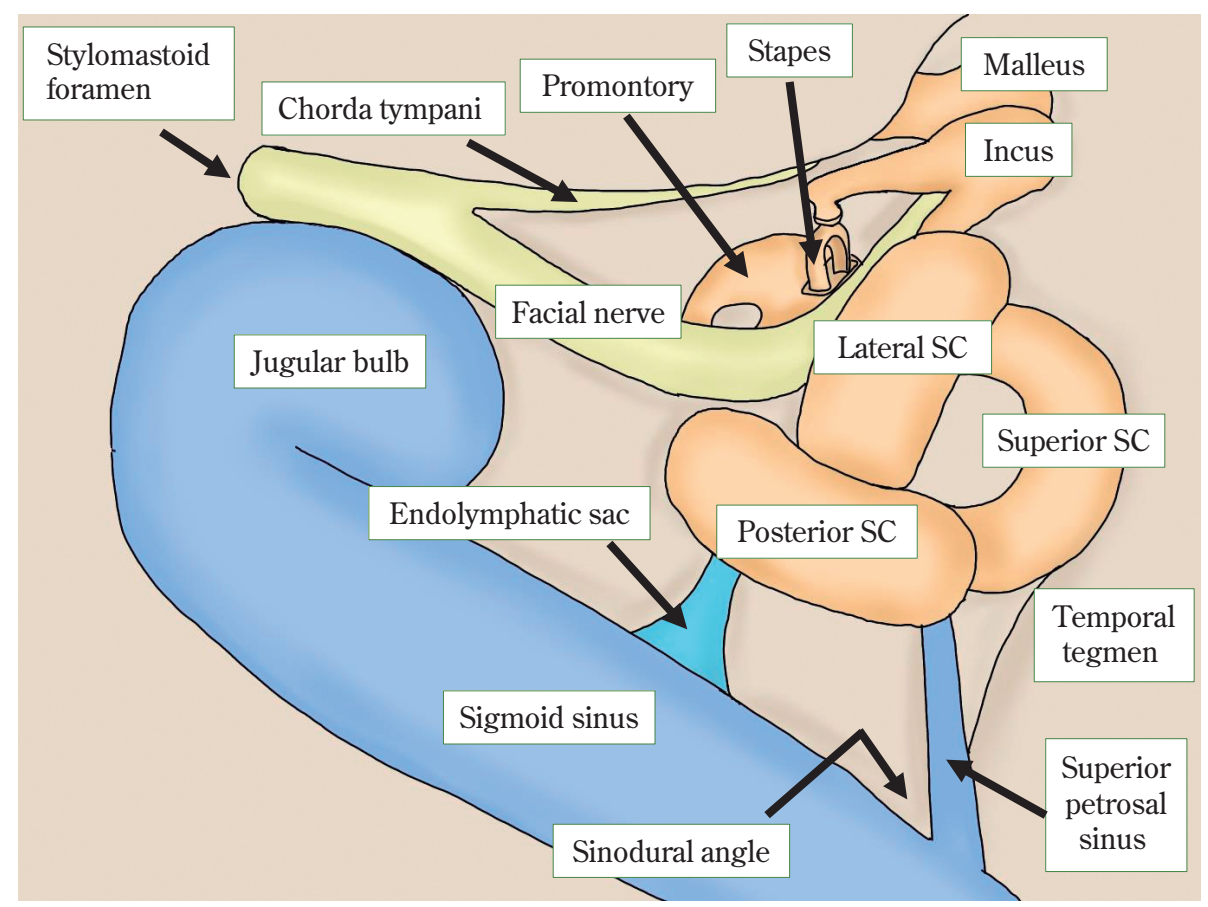

Fig. 1 Anatomy of the mastoid

The left mastoid is shown.

$\mathrm{SC}:$ semicircular canal

King $^{8)}$ が, 1973 年には Morrison and King ${ }^{9}$ が translabyrinthine-transtentorial approach を報告し, 以後 mastoid を削 除して病変へ到達する方法は, 1990 年代前半にかけて

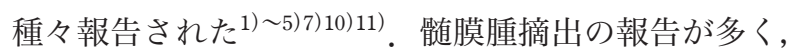
現在では錐体斜台部髄膜腫のほか, 下位脳神経由来の夕゙ ンベル型神経鞘腫，椎骨脳底動脈の血栓化脳動脈溜，グ ロームス腫瘍などの手術でも用いられる。

\section{アプローチとバリエーション}

Mastoidectomy を施行する posterior transpetrosal approach では, sigmoid sinus と三半規管の間から病変へ 到達する presigmoid approach を基本とする. しかし, こ のアプローチを単独で行うことは少なく, 多くの場合, anterior petrosectomy と合わせた combined petrosal approach，テント上下からアプローチする combined supra- and infratentorial approach, 三半規管を削除して内 耳道ヘアプローチする translabyrinthine approach, jugular bulb 周囲へアプローチする transjugular approach，それよ りも尾側の transcondylar approachなどと組み合わせて使 用される。脳幹を圧排する病変の場合, これに retrosigmoid approach を組み合わせて手術野を展開する.

\section{Mastoid の解剖}

Mastoid 内の中央には外側半規管, 後半規管, 上半規 管で形成される三半規管が存在し, S 状静脈洞から連続 する jugular bulb, 上椎体静脈洞と S 状静脈洞の連続部で 形成される sinodural angle が確認できる（Fig. 1)。上半 規管の頭側には側頭葉底面に相当する temporal tegmen が存在する. 外側半規管のすぐ尾側には顔面神経の tympanic segment があり, それは急峻に角度を変え mastoid segmentへと連続していく.

\section{手術の実際}

体位は側臥位とする，頝部が短い方や筋肉質で肩が術 野確保の妨げとなる場合には, 肩を前に倒し park bench position としてもよい. 上半身はできるだけ手術台の端 に寄せ，腰部は屈曲させて術後の腰痛を防止する，肩は 尾側に毫引するが, 力を加えて尾側へ旁引すると術後の 䅡部痛の原因となるので, 術野側に戻らない程度で十分 である、頝部は屈曲させ，少し顎を前方へ出すようにす る.この際，頋と煩骨との間に 2 横指の空間を確保し， 静脈灌流障害, 気道閉塞, 挿管の過挿入を防止する ${ }^{16) 18)}$.

手術台の背板は約 $20^{\circ}$ 挙上し, 術野を心臓の位置より 

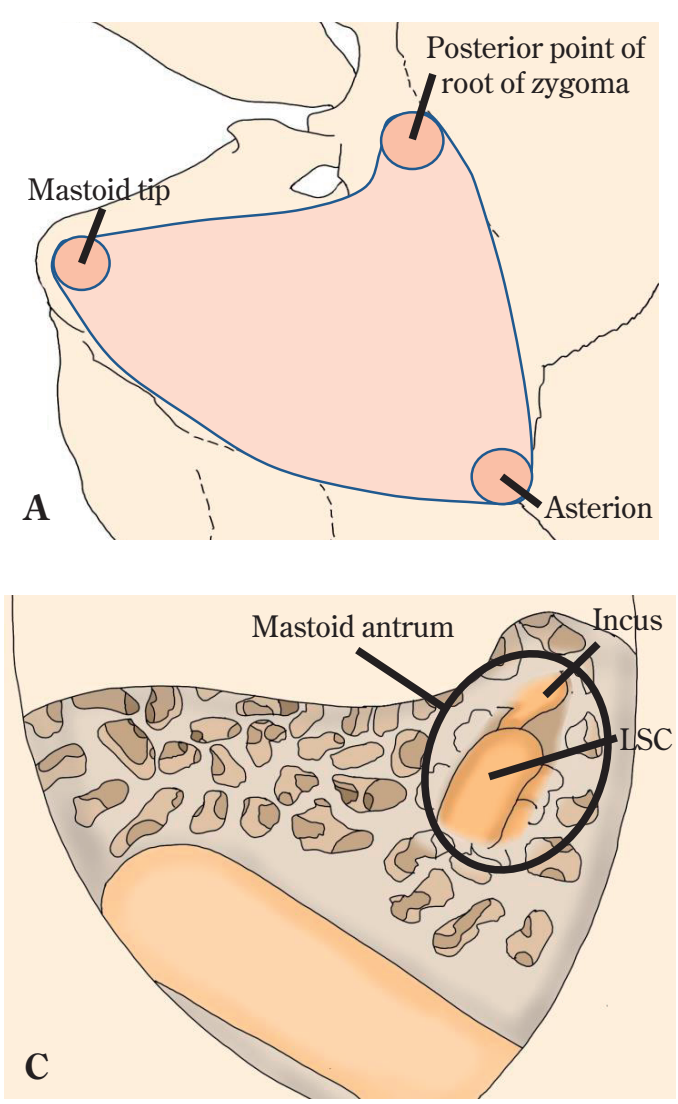
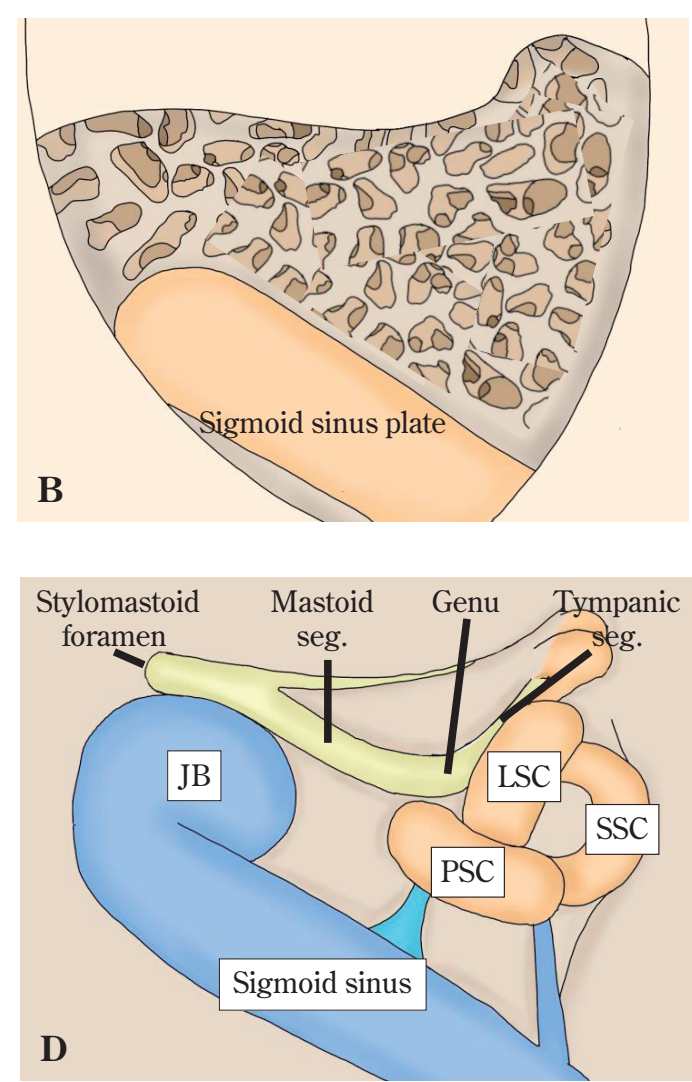

Fig. 2 Mastoidectomy procedure in stepwise detail

The left mastoid is shown.

A : Anatomical landmarks for mastoidectomy. A triangular area was drilled to facilitate mastoidectomy with the posterior point of the root of the zygoma, mastoid tip, and asterion as vertices.

B : Exposure of the sigmoid sinus plate. The sigmoid sinus plate was initially exposed.

C : Identification of the mastoid antrum. The mastoid antrum was then identified at the ventral and medial portion of the sigmoid sinus plate. The lateral semicircular canal and incus are situated inside the mastoid antrum.

D : Exposure of the fallopian canal and the semicircular canals. The structures inside the mastoid were exposed.

JB : jugular bulb, LSC : lateral semicircular canal, PSC : posterior semicircular canal, seg. : segment,

SSC : superior semicircular canal

も高くなるようにする．実際に当院の症例で測定すると $17.2 \pm 2.4^{\circ}\left(15 \sim 22^{\circ}\right)$ であった. vertex は downとして床 面側に軽度側屈させる。この際, 過剩になると術後の頝 部痛が起こるので, 皮膚切開部が平坦になる程度の側屈 で十分である. 小脳テントに圧排操作が加わり trigeminocardiac reflex による徐脈, 心停止の可能性が危惧され る場合は心臟ペーシングの準備を考慮する。当施設では 迷走神経に圧排操作が加わる場合にも，念のため経皮 ペーシングを準備している.

皮膚切開は毛流に対して $45^{\circ}$ となるように“V”字状と している ${ }^{16) 18)}$. 毛流に $90^{\circ}$ の皮膚切開が最も創が目立た ないが，これでは横切開となり術野の展開ができない. “C”字状もよいが, 毛流と平行になる部分ができてしま
うのが欠点である. 短頝で筋肉質の場合には, mastoid尾 側の術野を展開するため, 皮切を尾側へ延長する。その 際には創が皮膚の㱀壁に一致するように配慮すると, 術 後, 短髪の方でも創跡は目立たない16).

皮膚切開から後頭骨露出までは簡潔に 3 steps で行 う ${ }^{16) 18)}$. Step 1 として, 皮弁翻転後に筋膜を採取する.

Step 2 として，胸鎖乳突筋を腹側へ翻転する。そうする と頭板状筋が露出されるので step 3 として頭板状筋より も内側の筋群を一塊として尾背側へ翻転する。この際, 筋肉の発達や静脈叢の発達程度により disorientation と なることがあり，椎骨動脈の損傷が危惧される。そのた め, 大後頭孔を背側に辿り, 尾側で環椎後弓上縁をみつ けた後, 今度はそれを腹側へ辿り環椎の J-groove を目印 

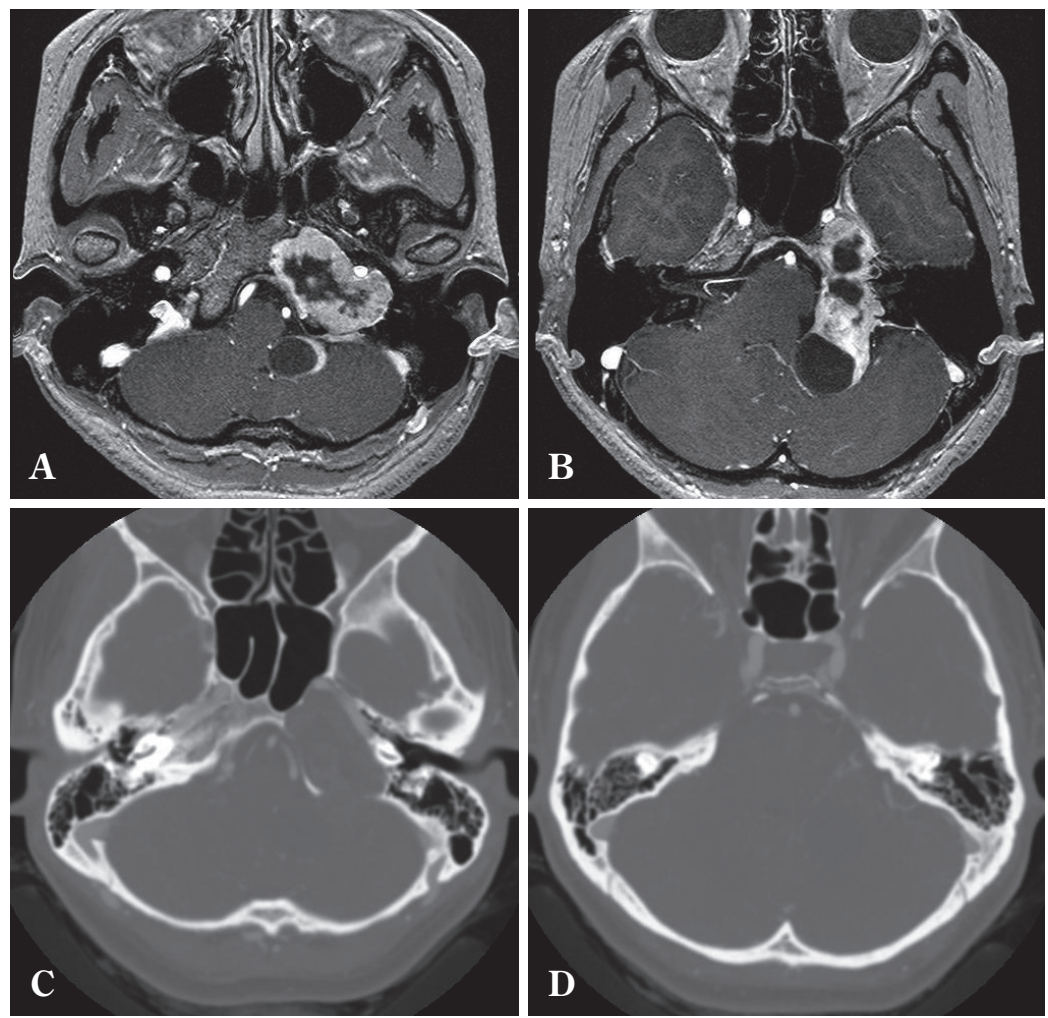

Fig. 3 Contrast ${ }^{-}$enhanced $\mathrm{T}^{-}{ }^{-}$weighted images and computed tomography prior to surgery

A, B : A dumbbell-shaped jugular foramen tumor is shown.

C, D : The deep portion of the mastoid is eroded by the tumor.

として椎骨動脈をみつける方法が, 安全で簡便である ${ }^{14)}$. 後頭骨から mastoid が露出された後は，ドリルを用い て骨溝を作成し，溝を paper thinにした後，ケリソンで 骨を除去し, craniotomy とする ${ }^{16)}$ 。その後, mastoidectomy（後述）を行い, 病変に応じて骨削除範囲を調整す る.

閉頭時，presigmoid の硬膜はあらかじめ採取しておい た筋膜で極力 watertight となるよう形成する。その後, mastoid antrum を筋膜で覆い, mastoid 内の空隙には腹部 より採取した脂肪片を充填する. Mastoidの表面は，皮 質を温存した場合には骨片で，皮質ごと骨削除した場合 には錐体骨形成用のアパセラムで形成する。Craniotomy 時に採取した骨片をチタンプレートで固定し，後頭骨を 形成後, 筋群は元の位置に戻す。

\section{Mastoidectomy の実際}

煩骨弓の根元である root of zygoma の少し後ろに相当 する posterior point of root of zygoma, 乳様突起先端部,
アステリオンの 3 点を囲むような三角部を骨削除してい く（Fig. 2A）。この際，1 力所を深く削るのではなく，均 一に骨削除していく ${ }^{15) 17)}$.

すると S 静脈洞に相当する sigmoid sinus plate という 骨皮質の高まりが出現するので，これをきれいに露出す る (Fig. 2B)。乞の後, sigmoid sinus plateの腹側を骨削 除していくと mastoid antrum と呼ばれる大きな空洞が出 現してくる(Fig. 2C)。この中にある骨隆起が外側半規管 であり，その腹側には incus が確認される ${ }^{12)}$. 基本的に sigmoid sinus plateから mastoid antrum までの間には重要 構造物はない。

この外側半規管を目印として後半規管と上半規管を露 出する (Fig. $2 \mathrm{D}$ )。顔面神経の mastoid segment は走行の バリエーションが多いので，頭側か尾側のどちらか一方 よりみつける ${ }^{13)}$ 。頭側で顔面神経を同定する際の指標は genu と呼ばれる屈曲部である。外側半規管に隣接する tympanic segment は，外側半規管と後半規管の接合部近 傍で急峻に角度を変え尾側へと走行していく。この屈曲 部が genu であり, バリエーションが少なく, 外側半規 

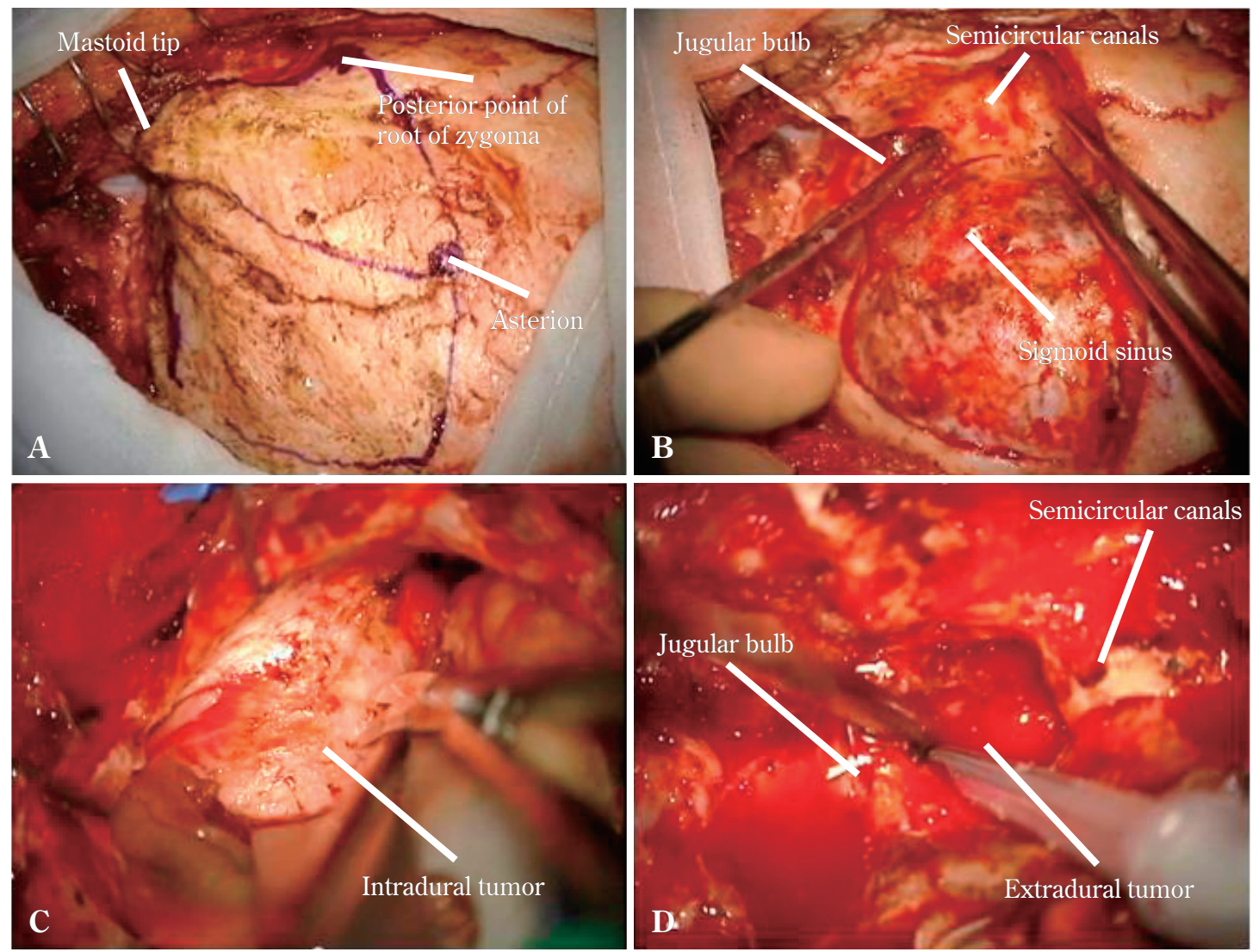

Fig. 4 Photographs captured during surgery

A : The occipital bone and mastoid were exposed. The areas where occipital craniotomy and mastoidectomy were performed on were marked.

B : Following cosmetic mastoidectomy, the semicircular canals and jugular bulb compressed by the extradural tumor were exposed.

C : After dural opening, the intradural tumor was totally resected.

D : A subcapsular dissection of the extradural tumor was performed from the space between the semicircular canals and jugular bulb to protect the lower cranial nerves closely situated to the tumor capsule.

管の尾背側で確認できるという利点がある。しかし，非 常に骨が薄いので損傷に注意が必要である。一方，尾側 で顔面神経を同定する際の指標は，stylomastoid foramen 部分である. S 状静脈洞尾側で digastric ridge をみつけ, これを腹側に辿り, 顔面神経が stylomastoid foramenから 頭蓋外に出ていく部分で同定する. digastric ridge は，外 側からみると, digastric groove に相当し, 顎二腹筋後腹 が存在している. Stylomastoid foramen 近傍の顔面神経 は軟部組織に覆われているため，尾側から同定する方法 は顔面神経損傷の危険が少ないのが利点である。臨床的 には電気的モニタリングを使用し, 顔面神経の走行を適 宜確認しながら骨削除を行う。顔面神経の mastoid segmentをみつけた後は，背側の骨をさらに削除していき， 頝静脈球を露出する。

Presigmoid から硬膜内での術野を最大限確保する際に
は，後半規管を綺麗に露出することが重要である，後半 規管を外側から drilling していくと，背側部に庇状の骨が 残存し，硬膜翻転時にこの骨の突出が視野の妨げとな る。この opercular bone を残さないよう骨削除するため には，後半規管を露出した後，後半規管と presigmoid dura の間に吸引管を入れて術野を確保し，ドリルを奥に 入れて，バーの手前側，バーを地球に例え先端側を北半 球，シャフト側を南半球とすると，この南半球側に相当 する部分を使用して, 奥から手前へ引くように up-cut し ながらこの骨を除去する.

\section{代表症例提示}

31 歳の女性で, 頭痛を主訴に受診された。精査でダン ベル型の頝静脈孔部腫瘍を認めた（Fig. 3)。妊娠中であ 

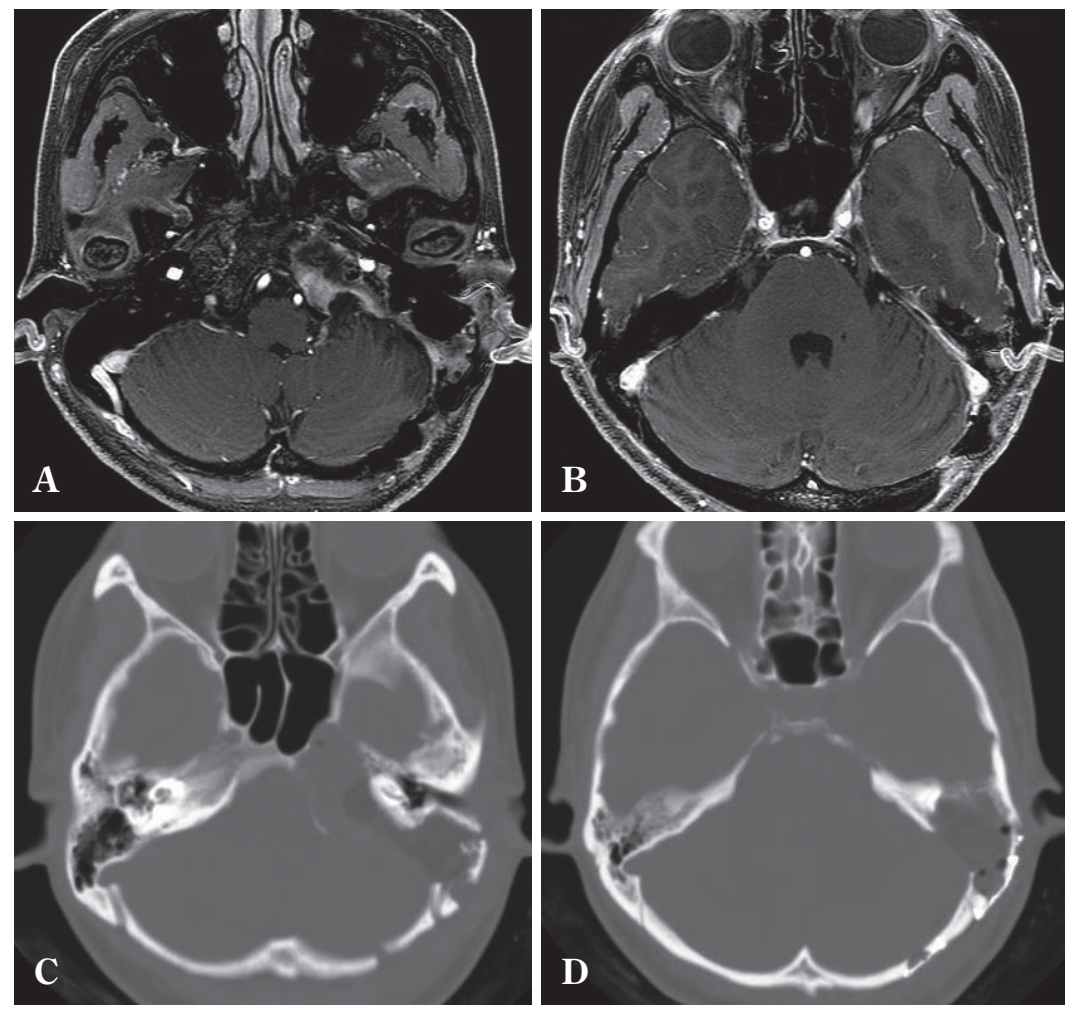

Fig. 5 Contrast-enhanced T1-weighted images 1 year after surgery and postoperative computed tomography

A, B : No tumor regrowth was observed.

C, D : The semicircular canals are preserved after mastoidectomy.

り，脳神経症状もなかったため経過観察としたが，半年 後の画像再検時に腫瘍が増大していたため，出産後に摘 出術を施行した。 Lateral suboccpital+transjugular approach を選択し, 顔面神経, 迷走神経, 副神経の電気 的モニタリングを行った。 Occpital craniotomy と mastoid の皮質骨を温存した cosmetic mastoidectomy を施行し， 硬膜外腫瘍を露出した（Fig. 4A, B)。硬膜内の腫瘍は被 膜ごと全摘し (Fig. 4C), 硬膜外腫瘍は頝静脈球と後半規 管の間より，被膜内摘出とした (Fig. 4D)。術後，一過 性の顔面神経麻痺が出現したが，下位脳神経症状を含め て恒久的神経脱落症状は出現しなかった。術後 1 年での 画像で腫瘍の再増大は認めていない（Fig. 5).

\section{結 語}

Posterior transpetrosal approach の概念, mastoid の解 剖，mastoidectomy の手順と臨床例につき提示した。詳 細な解剖学的知識に基づき頭蓋底手術を施行すること は，良好な手術成績，合併症回避につながると考元られ る。

\section{謝 辞}

Fig. 1 と Fig. 2 を描画した当講座の古村翔一先生に感謝しま す.

COI (conflict of interest) 開示

本論文の発表に関して開示すべき COI はありません.

\section{文 献}

1) Al-Mefty O, Fox JL, Smith RR : Petrosal approach for petroclival meningiomas. Neurosurgery 22: 510-517, 1988.

2) Ammirati M, Samii M : Presigmoid sinus approach to petroclival meningiomas. Skull Base Surg 2 : 124-128, 1992.

3) Hakuba A, Nishimura S, Inoue $Y$ : Transpetrosal-transtentorial approach and its application in the therapy of retrochiasmatic craniopharyngiomas. Surg Neurol 24: 405-415, 1985.

4) Hakuba $A$, Nishimura $S$, Tanaka K, Kishi $H$, Nakamura $T$ : Clivus meningioma : six cases of total removal. Neurol Med Chir (Tokyo) 17:63-77, 1977.

5) Hakuba A, Nishimura S, Jang BJ : A combined retroauricular and preauricular transpetrosal-transtentorial approach to clivus meningiomas. Surg Neurol $30: 108-116,1988$.

6) Henderson J: Communication to Neurosrugical Society of Australasia.(Unpublished data). 1965.

7) Kawase T, Toya S, Shiobara R, Mine T: Transpetrosal 
approach for aneurysms of the lower basilar artery. $J$ Neurosurg 63:857-861, 1985.

8) King TT: Combined translabyrinthine-transtentorial approach to acoustic nerve tumours. Proc R Soc Med 63 : 780-782, 1970.

9) Morrison AW, King TT : Experiences with a translabyrinthine-transtentorial approach to the cerebellopontine angle. Technical note. J Neurosurg $38: 382-390,1973$.

10) Nishimura S, Hakuba A, Jang BJ, Inoue $Y$ : Clivus and apicopetroclivus meningiomas - report of 24 cases. Neurol Med Chir (Tokyo) 29: 1004-1011, 1989.

11) Sekhar LN, Schramm VL Jr, Jones NF : Subtemporal-preauricular infratemporal fossa approach to large lateral and posterior cranial base neoplasms. J Neurosurg $\quad 67: 488-499$, 1987.

12) Wanibuchi M, Friedman AH, Fukushima $\mathrm{T}$ : Photo Atlas of Skull Base Dissection. New York, Thieme, 2009, pp.267-292.

13）鮎㴊昌彦: Transmastoid Approaches. in 鰐㴊昌彦 (編), 福島孝徳, Friedman AH, 宝金清博 (監): 頭蓋底局所解 剖アトラス. 大阪, MCメディカ出版, 2009, pp.114-121.
14) Wanibuchi M, Fukushima T, Zenga F, Friedman AH : Simple identification of the third segment of the extracranial vertebral artery by extreme lateral inferior transcondylar-transtubercular exposure (ELITE). Acta Neurochir (Wien) 151: 1499-1503, 2009.

15) Wanibuchi M, Ohtaki M, Fukushima T, Friedman AH, Houkin K : Skull base training and education using an artificial skull model created by selective laser sintering. Acta Neurochir (Wien) 152: 1055-1060, 2010.

16）鰐㴊昌彦，秋山 幸功, 三國信啓：Lateral suboccipital retrosigmoid approach とその variation. 脳外誌 $23: 802-811$, 2014.

17) Wanibuchi M, Noshiro S, Sugino T, Akiyama Y, Mikami T, Iihoshi S, Miyata K, Komatsu K, Mikuni N: Training for skull base surgery with a colored temporal bone model created by three-dimensional printing technology. World Neurosurg 91:66-72, 2016.

18）鰐渕昌彦：大後頭孔近傍腫瘍に対する開頭術. No Shinkei Geka 45:645-654, 2017.

要

Posterior Transpetrosal Approach

鰐㴊 昌彦

錐体骨にまで病変が及ろ゙頭蓋底病変に対して, posterior transpetrosal approach は有用な到達法で ある. 1970〜90 年代前半にかけ多数報告されており, lateral suboccipital approach よりも腹側から の術野が得られるのが特徵である. 腫瘍性病変のみならず, 血管病変に対しても応用可能であり, 本 稿では mastoid の解剖と mastoidectomy を中心とした手術手技について解説する.

手術は側臥位で行い, 後頚筋群は損傷しないよう剝離し, 後頭骨と mastoid を露出する. 後頭骨を craniotomy した後, mastoidectomy を施行する. 㚘骨弓根部の背側, 乳様突起先端部, アステリオン の3 点を囲むような三角部を骨削除していき, sigmoid sinus plate, mastoid antrum を確認する. そ の後, mastoid antrum 内の外側半規管を目印として後半規管と上半規管を露出し, 顔面神経や頚静脈 球を同定する. 実際の手術で posterior transpetrosal approach を単独で行うことは少なく, 多くの場 合, 他のアプローチと組み合わせた手術野の展開が必要となる.

Posterior transpetrosal approach を施行するには, 詳細な解剖学的知識と確かな頭蓋底 drilling の技 術が必須であり, 必要かつ十分に術野を展開することが重要である. 